Polimorf Işık Erüpsiyonu: Erken Başlangıç ve Nadir Klinik Görünüm

\title{
Polymorphous Light Eruption: Early Starting and a Rare Clinical Appearance
}

Yalçın Baş ${ }^{1}$, Zennure Takc1 ${ }^{1}$, Havva Yıldız Seçkin ${ }^{1}$, Samet Özer ${ }^{2}$

1Gaziosmanpaşa Üniversitesi Tıp Fakültesi, Deri Ve Zührevi Hastalıkları Ana Bilim Dalı, Tokat

2Gaziosmanpaşa Üniversitesi Tıp Fakültesi, Pediatri Ana Bilim Dalı, Tokat

$\ddot{O} z$

Polimorf 1şık erüpsiyonu yaygın görülen idiyopatik fotoduyarlı bir dermatozdur. Ultraviyole radyasyon maruziyeti sonrası, ışı̆̆a maruz kalan deride, ataklar şeklinde gelişen skar yapmayan kaşıntılı papüller, veziküller ve plaklar ile tanımlanır.

Bu çalışmada, atakları 3 yaşında başlayan ve eritema multiforme benzeri döküntüleri olan bir vaka paylaşılmıştır. Bu olgu, atakların çok erken yaşta başlaması ve nadir klinik prezentasyonu nedeniyle sunulmaya değer bulunmuştur.

Anahtar kelimeler: Eritema multiforme, fotodermatozlar, polimorf 1şık erüpsiyonu

\section{Summary}

Polymorphous light eruption is a common, idiopathic photosensitivity dermatosis. It is characterized with non-scarring pruritic erythematous papules, vesicles or plaques that occur after ultraviolet exposure on light-exposed skin areas.

In this study, we introduce a case with erythema multiforme-like rash whose symptoms has started in 3 years old. This case found worthy to be presented owing to the onset of the attacks at a very early age and rarity.

Key words: Erythema multiforme, photodermatoses, polymorphous light eruption 


\section{Giriş}

Fotoduyarlılık normal hatta sınırlı ultraviyole 1şığına maruziyet sonrasında gelişen anormal bir tepki olarak tanımlanır. Bu durum var olan bir dermatolojik hastalığın şiddetlenmesi, yeni bir döküntünün ortaya çıkması ya da pruritus ve parestezi gibi subjektif semptomların gelişmesi şeklinde meydana gelebilir (1). Fotoduyarlılık erişkinlerde çocuklardan daha sık görülmekle birlikte vakaların \%25'i gibi önemli bir oranı çocukluk çağında başlamaktadır (2). Bu hastalıklardan çocukluk çağında en s1k görüleni ise en yaygın idiyopatik fotodermatoz olan polimorf 1şık erüpsiyonudur (PIE) (3).

PIE güneş 1şı̆̆ına maruziyet sonrasında, genellikle sadece temas bölgelerinde gelişen polimorfik lezyonlarla karakterizedir. Vakaların büyük bir oranı erişkin yaşlarda görülmekle birlikte \%10’u 14 yaş altında, \%4'ü 5 yaş altında başlamaktadır (3). Yapılan birçok araştırmaya rağmen etiyolojisi ve hastalığı oluşturan mekanizmalar tam olarak ortaya koyulamamıştır. Ancak olguların yaklaşık yarısında aile hikayesinin pozitif olması genetik yatkınlığın önemini göstermektedir (4).

\section{Olgu}

6 yaşındaki kız çocuğu kollarında ve yüzünde bir gün önce başlayan kaşıntılı döküntüler nedeniyle pediatri polikliniğinden konsulte edildi. Şikâyetlerinin 3 yıldır her sene bahar döneminde tekrarladığ 1 ve yaz boyunca azalarak ataklar şeklinde seyrettiği öğrenildi. Lezyonların kaşıntılı olduğu ve 3-4 gün içinde iz bırakmadan koybolduğu anamnezi alındı. Hastanın dermatolojik muayenesinde; yüzde özellikle yanaklarda çok sayıda $0,1-0,5 \mathrm{~cm}$ çaplarında, eritemli zeminde, yer yer papül ve veziküller; kollar ve el sırtında 0,3-4 cm arasında değişen çaplarda çok sayında eritemli zeminde hedef tarzında döküntüler tespit edildi (Şekil 1, 2). Eski tekrarlayan lezyonlara ait skar dokusu ise izlenmedi.

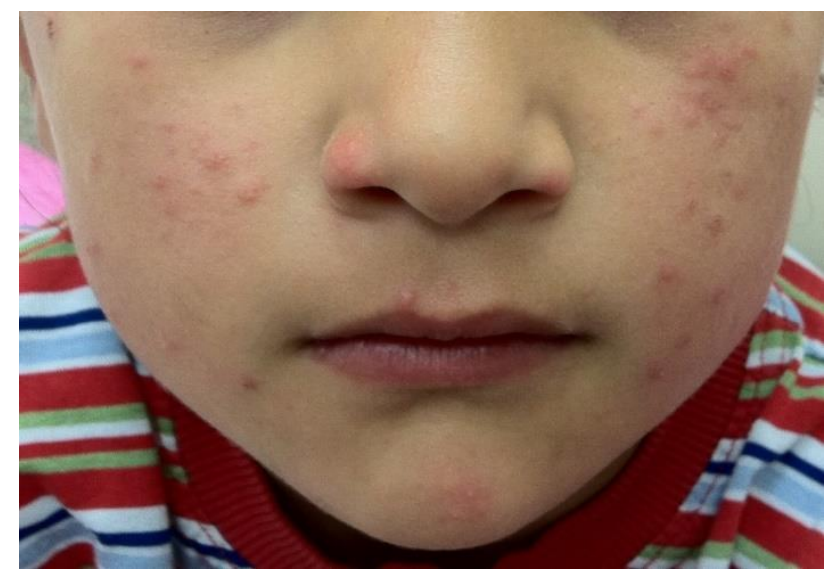

Şekil 1. Yüzde papüler ve papüloveziküler lezyonlar.

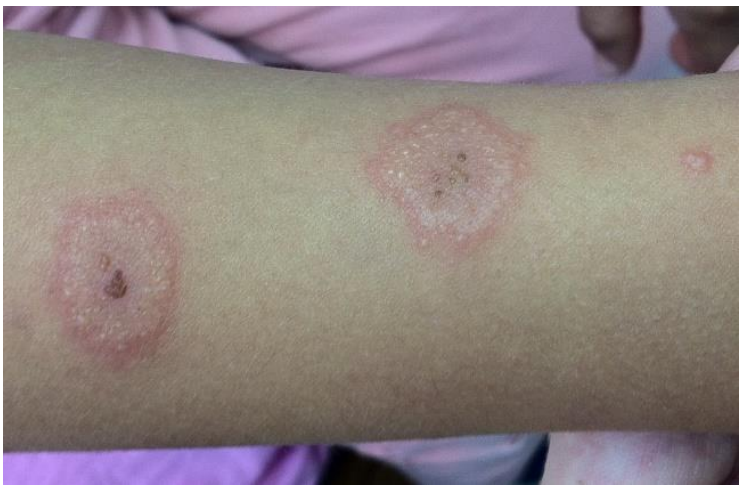

Şekil 2.Kolda hedef tarzı lezyonlar

Hemogram, rutin biyokimyasal tetkikler ve ANA normal sınırlar içinde bulundu. Hastaya klasik anamnez ve klinik bulgularıyla PIE tanısı koyuldu. 


\section{Tartışma}

Pediatrik yaş grubunda fotoduyarlılık ile seyreden bir çok hastalık ve sendrom bilinmektedir (Tablo 1). PIE, juvenil bahar erüpsiyonu, hidroa vaksiniforme, aktinik prurigo ve solar ürtikerin yer aldığ idiyopatik fotodermatozlar ise çocuklarda en sık görülen fotoduyarlı patolojilerdir.

Tablo 1: Çocuklarda fotoduyarlı patolojiler.

\begin{tabular}{lll}
\hline Grup & & \\
\hline İdiyopatik fotodermatozlar & PIE & Solar ürtiker \\
& Aktinik prurigo & Hidroa vaksiniforme \\
Şiddetlenen dermatozlar & Juvenil bahar erüpsiyonu & \\
& Atopik dermatit & Liken niditus \\
& Psoriasis & Herpes simplex \\
Ekzojen ajanlar & Liken planus & Darier hastalığı \\
& İlaçlarla indüklenen & Fitofotodermatit \\
& fototoksisite & \\
Besin eksikliği & İlaçlarla indüklenen fotoalerji & \\
Genodermatozlar ve & Pallegra & \\
metabolik bozukluklar & Xeroderma pigmentosum & Porfiriler \\
& Cockayne sendromu & Hartnup hastalı̆̆ı \\
& Rothmund-Thomson sendromu & Smith-Lemli-Opitz sendromu \\
& Trichothioodystrophy & Kindler sendromu \\
& Bloom's sendromu & \\
\hline Konnektif doku hastalıkları & Lupus eritematosus & Juvenil dermatomiyozit \\
\hline
\end{tabular}

Metabolik bozukluklar ve genodermatozlara bağlı fotoduyarlılık genellikle 1 yaşından önce hatta doğumdan sonra haftalar içinde ortaya çıkarken, idiyopatik fotodermatozlar genellikle okul çağı döneminde başlarlar (5). Ortak özellik olan fotoduyarlılık haricinde hastalıkların kendine özgü klinikleri sayesinde ayırıcı tanıya gidilebilir. Özellikle bu hastalık gruplarından metabolik bozukluklar ve genodermatozların erken fark edilmesi, bu hastalıkların mortalite ve morbiditesinden korunma adına önemlidir.

İdiyopatik fotodermatozların tanısında yardımcı olabilecek yeterli laboratuvar tetkikleri mevcut değildir. Ancak iyi bir anamnez ve klinik muayene ile tanı koymak mümkündür. $\mathrm{Bu}$ hastalıklardan hidroa vaksiniforme güneş teması sonrası oluşan eritemli maküllerin vezikül ve büllere dönüşümü ile karakterizedir. İyileşen bu vezikül ve büllerin sonrasında suçiçeği benzeri skarların izlenmesi PIE ile ayırıcı tanısında önemlidir (6). Solar ürtiker güneş temasından sonra dakikalar içinde 
gelişen ürtikeryal lezyonlar ile tanımlanır. PIE döküntülerinin aksine lezyonlar ürtikerde olduğu gibi genellikle birkaç saat içinde iz bırakmadan kaybolur (6). Aktinik prurigo çoğunlukla güneş gören yerlere lokalize yer yer krutlu, kaşıntılı papüller ve nodüllerle karakterizedir. Yaz aylarında lezyonlar artış göstermekle birlikte kış aylarında da çoğunlukla şikayetler devam eder. Aktinik prurigo günümüzde PIE’nun kış aylarında devam eden persistant tipi olarak kabul edilmektedir (6). Juvenil bahar erüpsiyonu sıklıkla erkek çocuklarda, özellikle kulaklarda yerleşmiş papül ve veziküllerle seyreder. Bu lezyonlar genellikle iz bırakmadan ya da minimal skar bırakarak iyileşirler. Juvenil bahar erüpsiyonunun da PIE’nun bir varyantı olduğu düşünülmektedir (7)

PIE genellikle 2. ve 3. dekatta gözlenir ve kadınlarda erkeklerden daha sık rastlanmaktadır. Klinik olarak yatkınlığı olan bireylerde güneş ışığına maruziyetten birkaç saat ile birkaç gün sonra özellikle temas bölgelerinde simetrik döküntüler meydana gelir. $\mathrm{Bu}$ döküntüler papüler, papüloveziküler, eritemli plaklar gibi çok farklı karakterde polimorfik lezyonlar şeklinde olabilir. Ayrıca daha nadir olarak eritema multiforme benzeri lezyonlar da görülmektedir (8). Karakteristik şekilde bu lezyonlar hidroa vaksiniformeden farklı olarak skar dokusu birakmazlar ve soler ürtikerden farklı olarak birkaç gün sebat ederler. Ek olarak semptomların ilkbahar veya yaz aylarının başında başladığı ve güneşe karşı doğal bir desensitizasyon gelişmesi nedeniyle yaz aylarının sonlarına doğru hafiflediği gözlenir $(8,9)$. Hastalara PIE tanısı klinik muayene bulguları ve öykü ile konulmaktadır. Lezyonsuz dönemde UV radyasyon uygulanarak yapılan provokatif fototestler teşhis koymada yardımcı olabilir. Tanısal bir laboratuvar testi yoktur. Ancak ayırıcı tanıda antinükleer antikorlar lupus eritematozusu ve porfirinler eritropoetik porfiryayı dışlamak için bakılabilir.

PIE kendi kendini sınırlayan ve eğer tekrar güneş 1şığına maruz kalınmassa 1-2 hafta içinde gerileyen iyi huylu bir hastalıktır. Tedavide ilk basamak; hastalar ve ebeveynlerinin güneş ışınlarının etkisi konusunda eğitilmesi, uygun kıyafet seçimi ve geniş spektrumlu güneş koruyucu kullanılmasıdır. Koruyucu önlemlerin başarısız olması durumunda topikal kortikosteroidler semptomların süresini kısaltabilir. Daha ciddi durumlarda ise sistemik kortikosteroidler kullanılabilir. Ek olarak bahar mevsiminin ilk aylarında, hastanın ışığa karşı toleransını arttırmaya yönelik koruyucu amaçlı fototerapi tedavisi uygulanabilir (10).

Sonuç olarak bu çalışmada, erken çocukluk döneminde başlayan ve eritema multiforme benzeri döküntüleri olan bir vaka sunulmuş ve çocukluk çağında karşılaşılan fotoduyarlı hastalıklara dikkat çekilmek istenmiştir. 


\section{Kaynakça}

1- Morison WL. Photosensitivity. N Engl J Med 2004; 350:1111-7.

2- Janse'n CT. Photosensitivity in childhood. Acta Derm Venereol Suppl 1981; 95:54-57.

3- Horkay I, Emri G, Varga V, et al. Photosensitivity skin disorders in childhood. Photodermatol Photoimmunol Photomed 2008; 24:56-60.

4- Janse'n CT. Heredity of chronic polymorphous light eruptions. Arch Dermatol 1978; 114: 188-190.

5- Grossberg AL. Update on pediatric photosensitivity disorders. Curr Opin Pediatr. 2013; 25: 474-9.

6- Chantorn R, Lim HW, Shwayder TA. Photosensitivity disorders in children: part I. J Am Acad Dermatol 2012; 67: 1093.e1-18.

7- Murphy GM. Diseases associated with photosensitivity. J Photochem Photobiol B 2001; 64: 93-98.

8- Hönigsmann H. Polymorphous light eruption. Photodermatol Photoimmunol Photomed 2008; 24: 155-61.

9- Millard TP, Hawk JL. Photosensitivity disorders: Cause, effect and management. Am J Clin Dermatol 2002; 3: 239-46.

10- Gülseren D, Elçin G, Karaduman A, ve ark. Polimorf 1şık erüpsiyonlu hastalarda desensitizasyon fototerapisinin etkinliğinin geriye dönük değerlendirilmesi. Turk J Dermatol 2012; 6: 1-6. 